\title{
Malícias Orientais (Pequenas Histórias Garotas, Alegres e Tristes de Costumes das Novas Conquistas) - Índia Portuguesa 1923
}

\author{
José DA SiLVA Coelho
}

\begin{abstract}
Organizado e anotado por Sofia Martinho (Instituto Camões, Universitdade de Leeds), Paul Melo e Castro (Universidade de Leeds) e Augusto Pinto (S. S. Dempo College of Commerce and Economics)
\end{abstract}

\section{1) $O$ pecado da marata}

Alta, forte, faiscando os olhos magnéticos, incendiários. Soraspotibay fascina, atrai e faz enlouquecer.

De raça marata, vestida de capdó apertadinho, o cass e o cholly muito ajustadinhos. Soraspotibay - os seios eretos e túrgidos vibrando de desejos, e as fartas ancas balouçando - é a mulher de fogo que aquece, entontece e faz desvairar.

A tez morena, um penduricalho dourado brincando no nariz, e manilhas de vidro tilintando nos braços robustos e bronzeados, essa Afrodite indiana magnífica, voluptuosa e tentadora - ilude o amor, aquece o sangue, e aniquila as energias...

Soraspotibay tem um pequeno negócio de frangos, galinhas e ovos, que vende a preços fabulosos.

Manhã cedo, ouvem-se os franguinhos piando, apertados nos seus dedos calosos. E Soraspotibay entra, negocia, faz mercancia e luta - impelindo-me ao pecado, à volúpia.

Depois, à exigência do custo dos franguinhos, junta-se a do custo dumas maravilhas, dum cholly ou dumas flores. E Soraspotibay, apertada nos meus braços sufoca; os seus olhos fuzilam raios de fogo; e, com um suspiro tênue, dormente, moribundo, cai vencida num aniquilamento voluptuoso.... 
Refrescado o sangue, volta-me a razão e com ela o arrependimento. Soraspotibay vai-se, mas o seu cheiro de raça - um odore di femmina característico - fica a perseguir-me como um remorso.

Meu banho, roupa suada, perfume no lenço, é tudo inútil - o remorso lá continua muito subtil, muito tênue, adejando no ar a perseguir-me, a desgostar-me...

E, quando à noite, esquecido enfim o pecado e o arrependimento, me deito envolto em lençóis levados e frescos - novamente o remorso transformado em tentação volta, importuno e provocador, a aquecer-me o sangue, a transtornar-me a razão...

Então, na escuridão do meu quarto, eu aperto no vácuo a saudade do farto busto, quente e palpitante, da Soraspoti; e, como um animal em cio, aspiro, com as ventas dilatadas, a recordação do seu cheiro fatal, o odore di femmina, o pecado da marata.

13 Novembro 1923

\section{2) $\mathrm{O}$ jejum do boto}

Sentado numa tábua, as pernas cruzadas, um pano vermelho enrolado à cinta e o busto nu, Ragunath, boto, o ventre vazio e enervado, todo ele magríssimo, rapado e lustroso, faz o pujah.

O seu pagode é pequeno e pobre: ninguém o frequenta, ninguém lhe dá esmolas. E, nestes tempos de egoísmo e impiedade, Ragunath, boto, solitário e triste, canta a purana às paredes frias e escuras do seu templo, conta lendas de heróis, cheias de abnegação e caridade; relata feitos de heroísmo e dedicação; e, nas ruínas dos muros negros e musgosos, a sua voz ecoando chora e desvanece.

O mundo está perdido; os seus sectários desprezam os ritos e costumes antigos; a caridade é-lhes desconhecida; a temperança e a castidade palavras vãs; e o amor de deus e do próximo mera doutrina.

Mas, Ragunath, boto, é um santo: ele despreza as riquezas e a farta comezaina; adora e ama o seu deus dia e noite; em jejum permanente, só come uma apa de arroz, quatro vezes por semana; e numa suprema abstenção dos prazeres mundanos, repele os amplexos voluptuosos e tépidos da rechonchuda e branca bottina. 
O seu kulagôr não lhe interessa; e o chaque e o baji-puri não o tentam; só de tempos a tempos o aveludado e alvo seio da mulher o perturba, inebria e enlouquece.

Então o virtuoso e pálido asceta roça a fronte pelo chão duro e frio; e, numa aflição medonha de perder o seu voto, grita, batendo as palmas: é jaiVittôl! é jai-Vittôl! é jai-Vittôl!!

Numa noite a tentação foi grande; o jai-Vittôl não lhe pôde acudir e, transpondo o chouqui húmido e frio, pedindo a Deus perdão dos pecados seus e dos homens, abriu, mansamente, a porta do quarto da sua mulher. E, à luz baça da candeia, Ragunath, boto, pálido, atônito e trêmulo, viu um abominável pecado, uma torpeza lancinante: a rechonchuda e branca bottina, repousando num sono plácido e angélico, a nudez marmórea do seu corpo escultural nos braços dum deuly!

Então o magro e triste asceta resignado, aceitando a vida do pecado da mulher como um castigo à fraqueza da sua carne, serenamente, volta ao templo, implora ao seu deus o perdão da lúbrica bottina, num fervoroso e prolongado pujah, e, à cintilação das estrelas, os ecos da purana ressoavam novamente pelas ruínas dos muros negros e musgosos do pequeno e pobre pagode...

15 Novembro 1923

\section{3) $\mathrm{O}$ prassad da bavina}

Viçosa, delgada e airosa, na mão a candeia acesa, Zaiú bavina, as pernas revolvendo o franzido do capòll, entrou no santuário do seu pequeno templo. Uma sombra de tristeza caía, com um pensamento constante, na sua fronte morena e misteriosa. E, à luz bruxuleante da lâmpada, o boto contemplava-a, com os olhos a brilhar de cobiça e o amor ardendo no seu peito nu e cabeludo.

Mas a bela Zaiú estava fria e melancólica; a mística bavina não compreendia a ardente paixão do boto; e, submissa, servindo o ídolo d'oiro e de marfim, pensava no seu seio estéril e inútil, onde a bênção do Porisrama não caía nunca.

Zaiú bavina não tinha filhos; ao serviço divino ia consumindo a existência; e quando, enfim, velha, feia, e sem forças, caísse doente numa esteira, Zaiú bavina desprezada pelos homens que a tinham amado morreria ao abandono, olvidada pelo deus a quem servia. 
E, a esse pensamento constante que a oprimia, cobrindo como um negro véu o seu futuro, o sangue esfriou nas suas veias azuladas; o arfar do seu peito teve intermitências cortadas de leves e curtos suspiros; e a mágoa, fazendo vincar a sua fronte enevoada, encheu-lhe os olhos de lágrimas quentes e amargas.

Então, numa súplica ardente ao Porisrama, ela implorou o doce anelo da sua vida; e, fervorosa e radiante, iluminada pela fraca luz da lâmpada, recebeu das mãos do bôtto o prassad da sua felicidade futura:

- Tu terás uma filha linda e meiga - disse-lhe o prassad vero e seguro - se dormires esta noite neste santuário calmo e abafado, sobre uma cama feita de folhas de tulôss...

À noite, alta noite, Zaiú bavina, o regaço cheio de ervas sagradas, abriu, ofegante e trémula, a porta do santuário. E o bôtto, apagando a luz da candeia, recebeu-a nos braços, palpitante e quente, ardendo na fé do vero e seguro prassad...

16 Novembro 1923

\section{4) $\mathbf{O}$ malsuth da vanina}

$\mathrm{Na}$ penumbra discreta da sua pequenina loja, onde dos ananases expostos se evola o aroma tentador, Sundorabay, a bela e branca vanina, perdeu o malsuth d'oiro do seu nôth que se desmanchou.

Seu marido, o vanino, astuto e trapaceiro, anda por longe em negócio de fruta. E Sundorabay, com as brancas e gordas pernas inquietas, e o busto perfeito e forte inclinado, rebusca o seu malsuth d'oiro que não encontra. Mas os seios, redondos e túrgidos, estalam o seu choly de seda velha; e, no desatino da sua preocupação, o brâmane vizinho, esquecendo a sua loja e a sua mercancia, contempla-a de pé, mudo, estático, e perturbado.

A noite vai caindo lentamente; a escuridão na loja é perfeita; os lojistas fecham os taipais dos balcões; e o silêncio se alastra e a solidão no pequeno mercado é completa.

Mas Sundorabay vanina é persistente; o seu malsuth d'oiro, ela o procura inutilmente; e, no desalinho da sua aflição, os dois seios, gordos e túrgidos, alvejam estremecendo, no lusco-fusco da pequena e abafada baiúca.

Então o vizinho brâmane, fechando a sua botica, acudiu solícito em seu auxílio. Rebuscaram os dois, na palha caída, o malsuth com impaciência; revol- 
veram os cestos de fruta madura, os caixotes de arroz e do sãon, e os boiões do óleo de coco e dos tiliôs. E, quando, enfim, o marido vanino regressou, noite fechada, a sua lojinha, encontrou a vanina Sundorabay rebuscando ainda o seu malsuth d'oiro, nas pregas do pundvém do vizinho brâmane...

17 Novembro 1923

\section{5) $\mathrm{O}$ voto da xettina}

À luz mortiça e pálida da candeia, ante a pequena estátua dourada do Maharuty, na solidão misteriosa e quieta da noite tépida e escura do mês de Sravou, Sudirabay xettina chora e soluça, lamentando o abandono em que Elpindra xette a deixou, desde o dia do seu foli-chaben.

Ela sabe que o infiel e devasso marido, faltando ao estatuto de sábio e justo Manú, ama e procura a perversa Mogarim, a venal e impudica naikina que o atrai e o retém.

A noite esfria no silêncio do seu quatro úmido e triste; lá fora à cintilação das estrelas um mocho pia agoirento; e a pequena Sudira, trêmula e medrosa, aconchega-se mais e mais ao Sri Maharuty, que, de olhos muitos abertos, contempla apaixonado, o rosto, original e meigo, da juvenil e linda xettina.

Então, mimada pelo seu olhar complacente, a pequena e linda Sudira, as faces coradas e o seio palpitante, faz um voto solene e cheio de fé. E, despindo o cholly de seda e o sári de bordo de galão, perante os olhos ávidos e inflamados de Maharuty, expondo a maravilha do seu pequeno e branco corpo de alabastro; segreda-lhe ao ouvido, num murmúrio terno e acariciador como a brisa da madrugada roçando pelos arrozais:

- Sri Maharuty! Este meu corpo, a minha única riqueza dar-to-ei se...

Mas, antes que concluísse o voto, Maharuty, doído de amor e de paixão, saltando rápido e ligeiro, do seu minúsculo nicho doirado, apertando nos seus braços o branco e flexível corpo da pequena e linda Sudira, com um beijo ardente e sem fim, tapou-lhe a rósea boquinha...

A brisa da madrugada soprava ligeira, fazendo trepidar as altas palmas dos coqueiros. Os trilos dos moruonis ouviam-se ao longe saudando os primeiros alvores da madrugada. E a pequena e meiga Sudira, aquecida nos braços quentes d'amor do seu deus, sentiu uma doce languidez invadir o seu alvo e casto seio. 
Mas, à luz pálida e indecisa da madrugada, a ingênua e inocente xettina olhando o rosto, real e verdadeiro, do Maharuty feito homem, teve um pequeno sobressalto: as feições do deus pareciam-se extraordinariamente com as do jovem e amorável Sadossiva, o irmão mais novo do seu marido...

Então, presa duma grande emoção e ternura, apertou, consolada, nos braços o corpo estremecido; e os seus lábios, procurando a boca do deus adorado, juntaram-se num botão de rosa, ardente, perfumado e infinito...

19 Novembro 1923

\section{6) $O$ segredo da alparqueira}

Coxi, da casta alparqueira - casta ínfima, desprezível e infecta - passa graciosa e satisfeita pelas ruas poeirentas e cheias de sol. O seu rosto, redondo e lindo, tostado, dum louro de torrada quente, sorri, alegre e iluminado, aos homens que a olham encantados, retardando os passos, deslumbrados.

No seu fresco colo cor de âmbar onde trepida farta carne tentadora, uma fiada de coral sangra e estrangula. E nos seus roliços braços, que, balançando graciosos, estremecem e fazem sonhar, manilhas verdes tilintando; alegram e dão esperança...

Coxi, a alparqueira, passa risonha e bela, vestida de pano cor de folhas mortas, o cholly, de seda vermelha, apertando roscas saborosas. E nas fartas ancas, de curvas simétricas, sinuosas, duas depressões marcam - as palmadas que lhe deu o Brama quando a criou para este mundo.

Coxi, a alparqueira, sorrindo vai passando graciosa, duas covinhas no queixo, tornando-a mais bonita e apetitosa. E os seus grandes olhos, cismadores e luminosos, penetram, conquistam e dominam - o coração do cristão, do moiro, do brâmane, do vanino, do ourives e do marata...

Só Ramâcrisna, o xenoim, o puritano e rico suserano, volta a cara e cospe para o lado, de asco e de nojo, quando Caxi passa, donairosa e cobiçada pelas ruas poeirentas e cheias de sol. E, cuidadosamente, timidamente, receoso de sujar as sandálias e seus pés lavados e purificados, evita pisar as pegadas que vai deixando pequeninas e mimosas, a bela e fresca alparqueira, sorrindo, andando, encantando e perturbando... 
Caxi não tinha marido; amantes ninguém lhos conhecia nem suspeitava; mas a vida levava-a regalada e sem cuidados.

Isso despertou curiosidades e intrigas; e os da sua casta reunindo-se, uma noite, depois de grande bebedeira e zaragata, resolveram expulsá-la do seu grêmio.

Sem marido e sem trabalho donde vinha o dinheiro para Caxi levar vida de rosas? Um velho, alcoólico crônico, caquético e tinhoso, levantando-se trêmulo de delírio e de indignação revelou segredo:

- Era um demônio que lhe dava moedas luzidias, indo à noite, à alta hora, procurá-la à sua cabana escura!

Então os alparqueiros embriagados e amotinados, munidos de grandes archotes, cercaram e queimaram a velha e pobre choupana da linda e gorda Caxi.

$\mathrm{E}$, à luz brilhante das chamas, os alparqueiros, mudos de terror e de pasmo, da choça, pequena e humilde, da bela e cobiçada Caxi, viram sair - cuidadosamente, timidamente, receoso de sujar as vestes e o seu corpo lavado e purificado - Ramâcrisna, o xenoim, o puritano e rico suserano... o segredo da alparqueira...

20 Novembro 1923

\section{7) O engano de Luoximibay}

Foi no quarto dia da primeira lua, do chuvoso e úmido mês de Cartic, que Luoximibay Camotinim, a pequena e linda gulabxiutem, desabrochou, fresca e viçosa e ficou pela primeira vez bôxten. Seu marido Vitôl Camotte, um velho, gordo e pançudo, ao saber a novidade, que tão sofregamente esperava, ficou radiante e cheio de impaciência. Mas fingiu-se enjoado; fez uma careta e lançou uma praga. E, como uma leprosa infecta, e asquerosa, isolou a jovem e virginal Luoximi num quarto escuro, feio e triste...

Passou-se um dia; e mais três dias passaram-se também; e Luoximibay, enfim, lavada, penteada e purificada, saiu, linda e ruborizada, do seu cruel isolamento.

Então as belas e brancas mulheres da rica casa dos Camotins, cobertas de joias e sedas caras, toucaram-na de mogarins; assentaram-na num trono suntuoso, feito de papel e flores raras, ao lado do marido, o velho lúbrico e 
adiposo; e feito a garbadana, segundo o ritual da sua casta e família, fecharam os dois bem fechadinhos, numa discreta e perfumada alcova, com grande troça e gargalhada....

E, meia hora depois, quando todos em casa supunham Luoximibay emancipada, e livre dos infortunios tollés, as belas mulheres Camotins viram-na com maliciosa alacridade, dirigindo-se ao feio quarto escuro, onde na véspera estivera isolada, a ingênua e inocente gulabxiutem, supondo-se novamente bôxtem...

Mas, reconhecendo, mais tarde, o fatal e delicioso engano, a doce Luoximibay, voltou nos bicos dos pés; e, mansamente, sorrateiramente, desembaraçando-se dos pesados tollés e da sua touca de mogarins, entrou na sua alcova perfumada e, definitivamente, no grêmio das belas e brancas mulheres, da rica casa dos Camotins...

22 Novembro 1922

\section{8) O crime da bandorina}

Noite de mirgo, noite negra, ventosa e chuvosa; ribomba o trovão e raios fuzilam; e, ao rugido ululante e terrível do temporal, a sã e rigorosa Pondori; sozinha e triste, acocorada a um cantinho, chora, silenciosamente.

$\mathrm{Na}$ sua casinha abalada pelo vendaval, a umidade entra, incomoda e arrepia. Lá fora, as palmeiras esguias, sacudidas e açoitadas gemem magoadas, lamentam dilaceradas e, a cada soluço, o lindo corpo forte e brônzeo da vigorosa Pondori estremece e vibra de infinita mágoa.

Durante dez anos de casada, o seu farto e rígido seio ficara estéril e inútil; e, agora, porque a Lei Santa o mandava, ela, resignada e triste, cedera a sua alcova à pequena e magra Radá, segunda mulher de Naraim seu marido e seu senhor. E o seu coração sofria: o sangue aflito pulsava nas suas veias grossas e tímidas porque a outra lhe furtava as carícias, que por dez anos gozara...

O tufão feroz redobra de violência: o vento zune desenfreadamente, por entre a ramada das árvores seculares; a chuva impiedosa bate, como metralha devastadora, o fraco teto carunchoso da sua pequena casinha; e a bela e vigorosa Pondori, com os olhos a transbordar de lágrimas e o coração ralado de ciúmes, vela sozinha e triste, nessa noite tétrica e dolorosa, as núpcias da pequena e magra Radá com o seu marido Naraim.... 
Mas um tornado medonho e furioso passou uivando sinistramente, como uma vingança divina, aniquiladora e final, numa cavalgada infernal, destruidora e terrível - derrubando palmeiras, arrancando árvores, arrebatando o teto do pequeno quarto, e inundando o ninho de amor do pobre Naraim Bandori...

E quando a pequena Radá, aterrada e encharcada, saiu, tremendo e chorando, da sua alcova alagada, as lágrimas secaram, nos olhos da bela e vigorosa Pondori; e por entre o ribombo dos trovões, as suas gargalhadas cruéis, sinistras e vingadoras, ecoaram nas escuridão lúgubre da tormenta. Aquando da primeira noite de amor da pequena e magra Radá...

24 Novembro 1923

\section{9) $\mathrm{O}$ calote do Fottu-Xette}

Gongá Colavonta, a bela e rica bailadeira, vestida de pano de seda branca, emproada e penteada, bate os pés de arrelia e de impaciência, no mand de Fottu-Xette, o ourives mentiroso e caloteiro.

Nos seus braços gordos e tentadores, maravilhas d'ouro brilham, apertando os pulsos. No seu colo de cisne, onde farta carnação, provocadora, palpita quente, joias e pedrarias faíscam, deslumbram e perturbam. E a Gongá afogueada, raivosa e teimosa, parece uma vestal indignada, repelindo uma afronta amorosa...

Ela reclama as suas joias, que, há três meses, o xette lhe promete descaradamente; jura que não arreda o pé, desta vez sem as joias que quer imediatamente; e Fottu-Xette, o grande xendi entrançado pendendo pelas costas, vai martelando uma cadeia d'ouro, pacatamente.

Enfim, chegam a um entendimento: Fottu-Xette promete levar-lhe as joias à noitinha e quer a paga de amor com arrebatamento toda a noite até a manhãzinha...

À noite, Fottu-Xette, de cholló branco e ttopy de galão, depois de três longos meses de calotes e de mentiras, entregou à bela Gongá as suas ricas joias de ouro e de safiras.

Mas com a paga do seu trabalho, a da sua crônica mandria; e, paciente e resignado, por três longos meses, gramou, a comichão da bicharia, que a gorda Gongá lhe pregou, em uma única noite em que, no fim das contas, o amou... 25 Novembro 1923 


\section{0) A incredulidade do Velho Loeshimou}

À luz forte e incômoda dos kitsous, ao som de murdanga e do pequeno harmônio a nattók começa e o murmúrio da assistência cessa. E o velho Loeshimou atento e apaixonado, escuta o canto nasalado e trinado, do jovem Mucunda, que, vestido de pano e cholly de seda, coberto de joias e gagris, em requebros e meneios dá a ilusão perfeita duma bela e tentadora bailadeira.

Segue-se outra cena; e o jovem Mucunda, torcendo o corpo flexível avança, recua e, em pausas lentas e ligeiras, dança um estonteante decnim.

A ilusão é perfeita: uma ave, a esvoaçar ligeira, mais suavamente não pisaria o palco do que Mucunda a dançar, fazendo soar os gagris, com os seus pés leves e vaporosos. E o velho Loeshimou entusiasma-se: abre muito os olhos, abre muito a boca; e quando no fim da cena, num acelerado, rítmico e animado, de passos e de atitudes, o seio postiço de Mucunda arfa de fadiga, Loeshimou deslumbrado bate as palmas e grita:

- Xabassbay! Xabassbay!!

Então o velho perde de todo a razão e a seriedade. Doido de amor e de paixão, inquire: quer saber o nome do ator, e duvida: Mucunda! Um vapor! Não podia ser. Se havia marosca. Mulher com certeza era, uma autêntica bailadeira, que lá estava a dançar. Enganavam-no, burlavam-no, para se rirem depois da sua credulidade...

E, quando a nattók findou, Loeshimou, ardendo de paixão e d'amor, metendo-se por entre os bastidores, mansamente foi espreitar Mucunda a desapertar os trapos, que davam do seio a ilusão amena, arfando, tentadora e provocadoramente, ao dançar o decnim na cena...

28 Novembro 1928

\section{1) Amor de gounlina}

Rocuminim, a pequena gounlina, uma estátua de bronze, uma escultura antiga, de olhos sonhadores e olheiras virginais, curva a fronte respeitosa e tímida à entrada do seu amoroso estábulo da boiada. E Suriagi Ráo Ranes Pratapráo Sar Dessay, o grande senhor e rico fazendeiro, lançando um olhar altivo à pequena e humilde pastora, afaga o seu boi favorito - um nobre animal de arcaboiço de aço e chifres aguçados, ferozes e terríveis. 
Mas a pobre Rocuminim estremece; o seu coração pulsa desordenadamente; e, enleada e perturbada, baixa ainda mais a fronte, confundida, humilhada e ruborizada.

Ela ama o seu senhor que a tem ao seu serviço e que a despreza, humilha e esquece. Nunca ela o pode olhar de frente, ver o seu rosto adorado, e falar-lhe do seu coração, ardente e apaixonado, pulsando, constantemente, de segundo a segundo, no amor do grande Suriagi Ráo Ranes Pratapráo Sar Dessay.

Afinal, que é ela? Uma pobre pastora de casta reles, um objeto sem valor, uma gounlina ínfima, uma órfã abandonada, uma viúva sem lar, um pouco de cinzas dum ser já morto, onde no fundo, num recanto muito oculto, um tição aceso, um coração moço, ainda bate e palpita d'amor.

Mas esse coração revolta-se contra a injustiça humana; brada-lhe de dentro que o amor a nobilita e a iguala; e que naquele curral, onde os bois cépticos ruminam pensativos, a sua paixão, comprimida e espezinhada, tem o direito de se expandir, num suave olhar de nostálgico amor incompreendido...

$\mathrm{E}$, lentamente, levantando os olhos sonhadores, Rocuminim, a pobre pastora, a deusa de bronze, a estátua da Renascença, lançou um olhar, ardente e apaixonado ao rosto duro e altivo do grande e rico Suriagi Ráo Ranes Pratapráo Sar Dessay...

Então, Suriá, o astro do dia, espreitando curioso pela fresta estreita, viu rubro de furor e indignação, o Ranes de seu nome, o grande Suriagi, o rico Sar Dessay e Pratapráo, apertando nos seus braços augustos, com ternura e arrebatamento, Rocuminim, a pequena pastora, a estátua de bronze, a escultura antiga, a deusa da Renascença... a pobre e ínfima gounlina.

30 Novembro 1923

\section{2) O perfume da flor caída}

Finda a tarde envolta em névoa melancólica. Os passarinhos aos pares recolhem-se, cautelosos nas brechas misteriosas, ocultando os seus amores e cantares tímidos e receosos. E, ao bafo quente do mês de Pausa, as folhas do salgueiral caem mortas e amarelecidas.

A noite avança, a névoa condensa-se: a melancolia invade, como o fluxo da maré, a aldeia silenciosa e quieta, repousando à beira do rio plácido e ne- 
buloso. E, no palmeiral, envolta na escuridão sonolenta, sozinha, a porta da sua nobre casinha, a triste Kalian, a esbelta tarina, a flor do lótus, o amor da perdição, sonha e devaneia:

Vê-se andando por uma estrada longa, arenosa e macia, juncada de folhas e nenúfares. $\mathrm{O}$ sol nasce, alegre e luminoso, de bom augúrio, acariciador e amorável. A brisa suave refresca e inebria, consolando e perfumando a sua alma incompreendida. E os seus passos, leves e insensíveis, a levam à terra sagrada, onde, Crisna e Radá, Mahadeu e Parvoty, e Ramâ e Sitá, amaram e viveram felizes...

Mas o seu marido, um velho tary alcoólico e brutal, chega; e, como a pálida estrela que cintila e esvai ao arrebol da madrugada, o seu sonho se desvanece - a pobreza e a miséria instalam-se na sua casinha. Não há que comer: a fome aperta; e o marido, o grosseiro tary, madraço e vicioso, magoa-a, desgosta-a e desespera-a...

Cai a noite envolta em densa névoa melancólica; os passarinhos calam-se, assustados, na escuridão das brechas misteriosas; ouve-se cair no salgueiral dormente as folhas mortas, secas e amarelecidas; e um vácuo se faz no coração dolorido da triste Kalian, desprezada e magoada, ansiando pelo amor de alguém que a compreenda, a ampare, a acaricie e a estremeça...

Depois o sonho torna-se em realidade: a esbelta Kalian abandona o lar e vai andando por uma estrada dura e pedregosa. O sol no pino larga raios de fogo. A brisa para e a calmaria sufoca. E os seus passos, incertos e pesados, levam-na à terra da perdição, pelo caminho do vício e da corrupção.

Quando, enfim, chega a noite temerosa e escura, as trevas invadem o seu coração revoltado; a sua alma incompreendida cai no lodaçal da vida, no pântano da podridão; e, com as folhas que caem secas e amarelecidas, o perfume se esvai da flor caída, da alma incompreendida da triste e esbelta Kalian....

1 Dezembro 1923

\section{3) A consolação da dessaina}

De pé, no meio do seu palmar, a dessaina, desolada e condoída contempla a devastação, que fez o tufão, no arvoredo frondoso e verdejante. E os seus grandes olhos sonhadores pairam tristemente sobre as palmeiras derrubadas e sobre as grandes ramagens das mangueiras mutiladas... 
Do sol da manhã escoam-se raios brandamente, por entre as palmas úmidas dos coqueiros. As águas das chuvadas da noite correm, sussurantes pelos rigueiros próximos.

Pelo ar, que as trovoadas purificaram, borboletas voejam aos pares, perseguindo-se. Das poças de água lamacenta, sapos luzidios emergem, olhando assustados. E na fresca palha que desponta viçosa, saltões pulam, com ruídos arrepiantes.

A dessaina espraia o olhar, tristemente pelo palmar devastado, e calcula os prejuízos: quarenta palmeiras caídas agonizantes; três ramos enormes de mangueiras derrubadas, e uma rica jaqueira abatida.

Uma grande calamidade o sinistro da noite passada! Prejuízos incalculáveis que o furacão fez passar de terrível a devastador.

A dessaina avança a passos lentos até à beira do rigueiro próximo. Da outra banda, no palmar da vizinha Porbina, o vendaval fizera destroços maiores: as palmeiras tinham caído quase todas, esmagando as palmeirinhas pequenas e mimosas!

Então o seu rosto se iluminou de maldosa alegria; e com uma gargalhada estridente, argentina, escarnecedora e cruel, consolou-se com a desgraça alheia....

2 Dezembro 1923

\section{4) A inveja das flores de lótus}

Rubro, flameja o horizonte, como um grande mar longínquo, ardendo em chamas imóveis; vermelhos, sangram farrapos esguios de nuvens altas, como grandes feridas rasgadas por flechas aguçadas; e ao reverbero ardente do céu inflamado, as brancas flores de lótus coram nas águas tranquilas da fria lagoa, despeitadas e invejosas, ante as belas formas divinais do belo corpo dourado da pequena Zoiá.

A tarde finda, lentamente, no silêncio friorento e sereno mês de Falgun; uma neblina turva a atmosfera, orvalhando as palmas, imóveis, pendendo dos coqueiros frondosos; e a bela Zoiá lava o seu corpo maravilhoso, nas frias águas esverdinhadas da pequena lagoa tranquila.

Mas uma brisa ligeira sopra, encrespando a superfície prateada das lagoas, onde as flores de lótus nadam; a névoa tênue dissipa-se, arrastando em turbi- 
lhões ligeiros e fuscos; as palmeiras sonolentas espreguiçam-se, sacudindo as palmas úmidas; e a bela Zoiá sai do banho, tiritando, do seu corpo dourado escorrendo pérolas, em fiadas faiscantes de luz iriada, celestial, misteriosa.

Então o céu rubro-pardacento, num derradeiro lampejo do seu reverbero sanguíneo, iluminou, com um resplendor de fogo sagrado, a nudez divinal da bela Zoiá - como um hino à suprema Arte, à perfeição da Forma, à misteriosa harmonia das curvas transcendentes da Mulher. E as flores de lótus despeitadas e invejosas, vencidas e humilhadas, lentamente, servilmente, fecharam as suas corolas, em homenagem à suprema Arte, à perfeição da Forma, às harmoniosas curvas do corpo divinal e transcendente da bela e linda Zoiá.

14 Dezembro 1923

\section{5) A visão da ranina}

Chinicula, a ranina, filha do rico Ranes Sar Dessai, é como a flor infecunda, que vai murchando à aragem seca, do tempo implacável e destruidor. Viúva, ela esqueceu o marido, que morreu há anos sem a ver, sem a acariciar, sem a amar. Nunca lhe falam dele, nunca o seu nome é pronunciado na sua presença. Mas o seu sangue ainda quente e vivo faz pulsar o seu coração ardente, lembrando-lhe, constantemente, um esposo amado, jovem, lindo, garboso, que, em vão, expira de momento a momento.

Pela seteira estreita do seu quatro escuro, ela ouve os cucos chamando-se, ocultos nas copas verdejantes das árvores do parque.

Eles são felizes!

Têm liberdade e amor: vivem alegres e buliçosos; enquanto ela, filha-escrava dum grande senhor, fenece, miseravelmente, na sua triste reclusão opressora...

Uma luz dourada, saudosa, de fim do dia, entra pela seteira, como uma vaga esperança animadora. No teto, pombos negros arrulham amores e ciúmes, arrogantes, lembrando a vida, o vigor, a alegria. E, aos ruídos que vêm de fora, o sangue da Chinicula ferve; o seu coração pulsa, violento, reclamando o Amor, e o seu seio rijo estremece em ânsias desconhecidas, incompreendidas - mas sentidas e adivinhadas. 
Os cucos calam-se, a pouco e pouco pelo arvoredo; os pombos sonolentos emudecem nos beirais sombrios; e raio dourado do fim do dia esvai-se, morrendo lentamente... Então no negrume opaco do seu triste cárcere, a pobre Chinicula vê, numa visão dolorosa, o esposo ansiado, jovem, lindo, garboso, estendendo-lhe, com um sorriso admirável, os braços robustos e acariciadores. E a triste Chinicula, de joelhos, curvando a fronte, devotamente, beijando-lhe as sandálias de fios d'oiro, suavemente, nos seus lábios vermelhos só sente as lajes frias da sua reclusão, o pó da terra, as cinzas do Amor - enquanto mocho, piando dolente, lhe recorda que as núpcias dela serão com a Morte, e só com a Morte!...

15 Dezembro de 1923

\section{6) A quirtana de Deuquibay}

Ao môtto da aldeia a multidão acorre animada. É já noite fechada; e o bôtto acende as candeias alumiando a assistência. Os velhos acocoram-se a um cantinho; os jovens assentam-se pelo vasto pavimento embostado; as mulheres, numa alfombra, cruzam as pernas; e um aroma excitante de zaiôs e mogarins sufoca, entontece, enlanguesce...

$\mathrm{O}$ ardass toma o seu lugar; e, grave, solene, majestoso, começa o quirtana. Fala em Tucaram e Ramdass; prega a virtude, o sacrifício, a pureza, exalta a abnegação, o desinteresse, a castidade; e o seu olhar frio, mortiço e vago, espraia-se pelos ouvintes.

Mas, num momento de fraqueza, o diabo afugenta: amostra-lhe as gordas pernas tentadoras da bela Deuquibay, e um começo de coxa ebúrneo, provocante e carnudo, que, descobrindo-se por entre o cass desapertado, faz entontecer, perturbar, sonhar...

O severo ardass empalideceu, os olhos, muito abertos, faíscam; tresloucado, muda bruscamente de assunto; e, brando, afável, jovial, fala no amor, no gozo da vida, na beleza das deusas e nas suas formas magníficas, esculturais e marmóreas.

Descreve as suas fartas cabeleiras lustrosas, onde a luz do sol se reflete; os bustos maravilhosos, onde as curvas perfeitas do seio arfam; os quadris salientes, onde as linhas sinuosas das ancas balançam; as pernas gordas e bran- 
cas, onde a vista dos deuses se refresca; e, quando, enfim, vai falar no começo da coxa roliço e carnudo, que se entrevê por entre as dobras do cass, engasga, sufoca e para, estático, tremendo e desvairado...

À Deuquibay uma pulga picara; e, aflita, arrepiada, arreliada coçava, sofregamente, raivosamente, o ponto apetecido, o roliço e carnudo começo da coxa, da sua farta e provocadora carne descoberta...

20 Dezembro 1923

Recebido em 10/02/2011 e aprovado em 10/03/2011. 